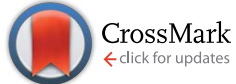

Cite this: RSC Adv., 2017, 7, 12464

Received 27th December 2016 Accepted 15th February 2017

DOI: 10.1039/c6ra28745j

rsc.li/rsc-advances

\title{
Determination of amino groups on functionalized graphene oxide for polyurethane nanomaterials: XPS quantitation vs. functional speciation $\uparrow$
}

\author{
Jakub Ederer, ${ }^{\text {*a }}$ Pavel Janoš, ${ }^{a}$ Petra Ecorchard, ${ }^{\text {b }}$ Jakub Tolasz, ${ }^{\text {b }}$ Václav Štengl, ${ }^{\text {b }}$ \\ Hynek Beneš, ${ }^{c}$ Magdalena Perchacz ${ }^{c}$ and Ognen Pop-Georgievskid
}

\begin{abstract}
Amino-functionalized graphene oxide was reacted with isocyanate monomer to evaluate the potential application of $\mathrm{GO}-\mathrm{NH}_{2}$ as a functional filler for the preparation of polyurethane nanocomposites. A set of advanced techniques (XRD, FTIR spectroscopy, Raman spectroscopy, and TEM) was used to characterize the functionalized samples, together with elemental analysis and XPS, which provided valuable information on the total $\mathrm{N}$ content and the nitrogen (chemical) speciation, respectively. In addition, a simple and fast spectrophotometric method was developed for the estimation of accessible amino groups (functional speciation). The method is based on the interaction of $\mathrm{NH}_{2}$ groups with the anionic dye acid orange 7 under appropriate conditions $(\mathrm{pH}=3.6)$ and shows good precision. It can be advantageously used for the fast evaluation of the $\mathrm{GO}-\mathrm{NH}_{2}$ reactivity with isocyanate monomer and its applicability as the polymer filler.
\end{abstract}

\section{Introduction}

Whereas physicists are still fascinated with the semiconducting properties, ${ }^{1}$ room temperature quantum effects ${ }^{2,3}$ and other unique phenomena of graphene and other low-dimensional carbon structures, chemists have found the chemistry of graphene somewhat poor ${ }^{4}$ and turned back to related laminar materials bearing various (mainly oxygen-containing) functional groups, many of which were introduced years before Geim and Novoselov's discovery - see, e.g., Hummers and Offeman's 'graphitic oxide'.

The new generation of graphene derivatives include hydrogenated graphene (graphane), fluorinated graphene (fluorographene $)^{\mathbf{6}}$ and graphene introduced with acetylenic chains (graphyne and graphdiyne), ${ }^{7}$ as well as sulfonated graphene ${ }^{8}$ or $\mathrm{N}$-containing reduced graphene oxide (GO). ${ }^{9}$ Introduction of the above-mentioned functional groups to the structure of GO improves not only the dispersibility and solubility of this material but also its reaction with other organic molecules,

${ }^{a}$ Faculty of Environment, University of Jan Evangelista Purkyně, Králova Výšina 7, 400 96 Ústínad Labem, Czech Republic.E-mail:jakub.ederer@ujep.cz; Fax: +420-475-284158; Tel: $+420-475-284-111$

${ }^{b}$ Department of Materials Chemistry, Institute of Inorganic Chemistry, AS CR v.v.i., Husinec-Řež Sq. 1001, 25068 Řež, Czech Republic

${ }^{c}$ Department of Polymer Processing, Institute of Macromolecular Chemistry, AS CR, v.v.i., Prague, Czech Republic

${ }^{d}$ Department of Chemistry and Physics of Surfaces and Biointerfaces, Institute of Macromolecular Chemistry, AS CR, v.v.i., Prague, Czech Republic

† Electronic supplementary information (ESI) available. See DOI: $10.1039 /$ c6ra28745j polymers and biological systems. ${ }^{\mathbf{1 0 - 1 2}}$ Nitrogenous functional groups incorporated into the carbon network can act as active sites for redox reactions. ${ }^{\mathbf{1 6}}$ Amino-functionalized carbon materials (GO, CNTs, graphene, etc.) have found numerous applications as nanofillers in polymer composites and coatings, ${ }^{\mathbf{1 7}}$ metal-free catalysts for oxygen reduction reactions, ${ }^{18}$ photoluminescent materials ${ }^{\mathbf{1 9}}$ and materials for immobilization or release of biologically active molecules. ${ }^{20}$ The amino groups are also responsible for the antimicrobial properties of the material, via their interaction with negatively charged cell walls. ${ }^{21}$

Commonly used methods of introducing amino groups into the GO structure, either during the synthesis of GO precursors or via the post-synthetic modification of GO, ${ }^{\mathbf{9}, 10}$ include doping under hydrothermal conditions with aqueous ammonia or hydrazine, ${ }^{10,13}$ ammonia plasma treatment at high temperature $^{14}$ or Hoffman rearrangement. ${ }^{15}$

Considering the application of GO as nanofiller for the preparation of GO/polyurethane nanocomposites with improved mechanical, thermal, electrical and flame retardant properties, good interfacial adhesion between the nanofiller and polymer matrix must be provided. ${ }^{17,22-24}$ Various methods of GO chemical modification have been developed to enable the creation of covalent bonding between GO and polyurethane precursors. ${ }^{25}$ The amino-functionalized GO was identified as a promising polymer filler, as its primary amino groups readily react with polyisocyanates. ${ }^{\mathbf{2 6 - 2 8}}$ Knowledges about the presence of the $\mathrm{NH}_{2}$ groups on the GO surface and about their accessibility for the reaction with isocyanates are fundamental to preserve the correct stoichiometry during the course of 
polymerization, ensuring a high polymerization degree of the final nanocomposites.

There are several methods for the analysis of ammonia surface functionalities ( $-\mathrm{NH}_{2}$ functionalities) or other type of functionalities. Basic methods used for the determination and evaluation of surface functionalities include spectroscopic techniques (XPS, FTIR, UV/VIS), as well as some less common methods, such as thermogravimetric analysis and contact angle measurement ${ }^{9,29}$ or titration methods. ${ }^{30,31}$ For example, XPS provides information about surface energies, surface composition and the morphology of the surface..$^{32-34}$

It is shown in this paper that the XPS technique in combination with some simple operationally defined procedures provides more comprehensive information on the usability of GO-NH $\mathrm{N}_{2}$ as a functional filler in polyurethane nanocomposites; whereas XPS distinguishes between various forms of nitrogen in the GO- $\mathrm{NH}_{2}$ molecule (chemical speciation), a newly developed indirect spectrometric method quantifies the fraction of $\mathrm{NH}_{2}$ groups that are available for further derivatization (functional speciation).

\section{Experimental}

\subsection{Chemicals}

All purchased chemicals were of analytical grade. Acid orange 7 (AO7) was purchased from Sigma-Aldrich (Germany). $\mathrm{NaOH}$, $\mathrm{CH}_{3} \mathrm{COOH}, \mathrm{H}_{3} \mathrm{BO}_{3}$ and $\mathrm{H}_{3} \mathrm{PO}_{4}$ for preparation of BrittonRobinson buffer (BRB) were purchased from Lach-Ner, Ltd. A stock solution of anionic dye was prepared in $\mathrm{BRB}(\mathrm{pH}=3.60)$. $\mathrm{KBr}$ (FTIR grade, $\geq 99 \%$ trace metal basis) was used for FTIR measurement and purchased from Sigma-Aldrich (Germany). Deionized water from a GORO Pharmpur system (Goro, Prague, Czech Republic) was used in all experiments with AO7. GO and ammonia-functionalized graphene oxide $\left(\mathrm{GO}-\mathrm{NH}_{2}\right)$ were purchased from Sigma-Aldrich (Germany). All chemical reagents $96 \% \mathrm{H}_{2} \mathrm{SO}_{4}, 85 \% \mathrm{H}_{3} \mathrm{PO}_{4}, \mathrm{KMnO}_{4}, \mathrm{NH}_{4} \mathrm{OH}, \mathrm{H}_{2} \mathrm{O}_{2}$ and ethylene glycol used for the synthesis of $\mathrm{GO}$ and $\mathrm{GO}-\mathrm{NH}_{2}$ were obtained from commercial sources: Penta, Ltd., and Lach-Ner, Ltd. Natural graphite was supplied by Koh-i-noor Grafite, Ltd., Czech Republic. Chemicals used in the reaction with isocyanate-butyl acetate ( $>99 \%$, Sigma-Aldrich, Germany) were stored over $4 \AA$ A molecular sieves prior to use: 1,6-diisocyanatohexane (HDI) (Desmodur ${ }^{\mathrm{TM}} \mathrm{H}$, Covestro, Germany) and dibutyltin dilaurate (95\%, Sigma Aldrich, Germany).

\subsection{Preparation of the samples}

2.2.1. Preparation of graphene. Graphene was prepared following a previously reported method. ${ }^{35}$ Briefly, natural graphite was exfoliated in an ultrasonic bath reactor $(20 \mathrm{kHz}$, $2000 \mathrm{~W}$, UIP 2000hd, Hielscher Ultrasonics GmbH, Germany) under high pressure ( 5 bar) in ethylene glycol. The graphene sheets were purified by dialysis with a Spectra/Por 3 dialysis membrane in distilled water.

2.2.2. Preparation of graphene oxide. GO was prepared by the oxidation of graphene. ${ }^{36}$ The dried graphene $(1 \mathrm{~g})$ was mixed with $\mathrm{H}_{2} \mathrm{SO}_{4}(60 \mathrm{~mL})$ for 10 minutes in a round-bottom flask.
Subsequently, $\mathrm{H}_{3} \mathrm{PO}_{4}(10 \mathrm{~mL})$ and $\mathrm{KMnO}_{4}(3 \mathrm{~g})$ were added. The reaction mixture was slowly heated to $40{ }^{\circ} \mathrm{C}$ for 48 hours. Additional $\mathrm{KMnO}_{4}(1.5 \mathrm{~g})$ was added and stirred for 3 days at the same reaction temperature. Afterwards, the mixture was cooled and added to an ice mixture with $\mathrm{H}_{2} \mathrm{O}_{2}(200 \mathrm{~mL})$. The resulting product was purified using a Spectra/Por 3 dialysis membrane in distilled water.

2.2.3. Preparation of amino-functionalized graphene oxide. $\mathrm{GO}-\mathrm{NH}_{2}$ was prepared using a slightly modified method published previously.$^{10}$ Briefly, a GO water suspension $(31 \mathrm{~mL}$, $0.256 \mathrm{~g} \mathrm{GO}$ ) was added to ethylene glycol $(53 \mathrm{~mL})$. The reaction mixture was transferred to a glass autoclave with mixing, and the aqueous ammonia solution was added $(6.5 \mathrm{~mL})$. The autoclave was kept at $150{ }^{\circ} \mathrm{C}$ for 12 hours. The resulting suspension was purified using a Spectra/Por 3 dialysis membrane in distilled water.

\subsection{Reaction of amino-functionalized graphene oxide with isocyanate}

GO- $\mathrm{NH}_{2}$ was dried at $80^{\circ} \mathrm{C}$ for 24 hours under vacuum. GO-NH $(25 \mathrm{mg})$ was dispersed in dried $n$-butyl acetate $(1 \mathrm{~mL})$ using an ultrasonic bath for 60 minutes. Then, 1,6-diisocyanatohexane $(2.17 \mathrm{mg})$ in $n$-butyl acetate solution was added, keeping the initial $\mathrm{NCO} / \mathrm{NH}_{2}$ molar ratio of $1 / 1$, and the mixture was sonicated for 60 minutes. Finally, a $1 \mathrm{wt} \%$ solution of dibutyltin dilaurate $(0.2 \mathrm{~mL})$ was added as a catalyst. The reaction mixture was kept at $40{ }^{\circ} \mathrm{C}$ under sonication during the reaction between GO-NH${ }_{2}$ and HDI.

The same experiment was also performed for the unmodified GO.

\subsection{Characterization of the samples}

The prepared samples were characterized by XRD, Raman spectroscopy, TEM, XPS, FTIR spectroscopy and elemental analysis (EA). XRD patterns were collected using a Bruker D2 diffractometer equipped with a conventional X-ray tube (CuKa radiation, $30 \mathrm{kV}, 10 \mathrm{~mA}$ ). Raman spectra were acquired with a DXR Raman microscope (Thermo Scientific), and 32 twosecond scans were collected with a $532 \mathrm{~nm}(3 \mathrm{~mW})$ laser under a $10 \times$ objective Olympus microscope.

The morphology of the samples and visual changes before and after sorption were inspected by high-resolution transmission electron microscopy (HRTEM) using a $120 \mathrm{kV}$ TEM microscope (FEI Talos F200X). Microscopic copper grids covered by a thin transparent silicon dioxide film or lacey carbon were used as specimen supports for TEM investigations. XPS measurements were performed using a K-Alpha + XPS spectrometer (Thermo Fisher Scientific, UK) operating at a base pressure of $1.0 \times 10^{-7} \mathrm{~Pa}$. The data acquisition and processing were performed using the Thermo Avantage software. All samples were analysed using microfocused, monochromated Al $\mathrm{K} \alpha$ X-ray radiation (400 $\mu \mathrm{m}$ spot size) with a pass energy of $200 \mathrm{eV}$ for survey spectra and $50 \mathrm{eV}$ for high-energy resolution core level spectra. The X-ray angle of incidence was $30^{\circ}$, and the emission angle was along the surface normal. The K-Alpha charge dual compensation system was employed during 
analysis, using electrons and low-energy argon ions to prevent any localized charge build-up. The obtained high-resolution spectra were fitted with Voigt profiles. The analyser transmission function, Scofield sensitivity factors, and effective attenuation lengths (EALs) for photoelectrons were applied for quantification. EALs were calculated using the standard TPP$2 \mathrm{M}$ formalism. All spectra were referenced to the $\mathrm{C} 1 \mathrm{~s}$ peak attributed to $\mathrm{C}-\mathrm{C}, \mathrm{C}-\mathrm{H}$ at a binding energy of $285.0 \mathrm{eV}$, which was controlled by means of the well-known photoelectron peaks of metallic $\mathrm{Cu}, \mathrm{Ag}$, and $\mathrm{Au}$.

The FTIR spectra of GO and GO- $\mathrm{NH}_{2}$ before and after sorption were measured by a diffuse reflectance Nicolet 6700 IR spectrophotometer (Thermo Scientific) in transmittance mode in the $400-4000 \mathrm{~cm}^{-1}$ range at 100 scans per spectrum with 4 $\mathrm{cm}^{-1}$ resolution. Raw FTIR data were processed utilizing the OMNIC 7.3 software. The samples for FTIR analysis were first lyophilized for 24 hours, subsequently ground in an agate mortar with $\mathrm{KBr}$ in a ratio from $1: 100$ to $1: 400$, and finally placed in a ball mill for 5 minutes. $\mathrm{KBr}$ pellets of $13 \mathrm{~mm}$ diameter were prepared using a hydraulic press $(80 \mathrm{kN})$ for 5 minutes. FTIR spectra of the reaction mixtures with isocyanate were measured using the attenuated total reflectance (ATR) technique on a Spectrum 100T FTIR spectrometer (PerkinElmer, USA) with a DTSG detector equipped with a Universal ATR diamond/ZnSe crystal. All spectra were recorded in the $650-4000 \mathrm{~cm}^{-1}$ range at 16 scans per spectrum with $4 \mathrm{~cm}^{-1}$ resolution.

Elemental analysis (EA) was performed on a PE 2400 Series II CHNS/O analyser (Perkin Elmer, USA).

\subsection{Spectrophotometric determination of the amino groups}

Adsorption studies were performed in $2 \mathrm{~mL}$ Eppendorf vials, to which a GO suspension $(200 \mu \mathrm{L})$, stock solution of AO7 (concentration range from $2.5 \times 10^{-4}$ to $4.5 \times 10^{-5} \mathrm{~mol} \mathrm{~L}^{-1}$ ) and BRB were added. For the equilibrium studies, the experiment was carried out for 3 hours at $25 \pm 1{ }^{\circ} \mathrm{C}$ to ensure that equilibrium was reached. Subsequently, the Eppendorf vials were centrifuged at 14000 RPM for 30 minutes. The equilibrium concentration of AO7 in the supernatant solution was determined using a UV/VIS spectrophotometer (Cintra 2020, GBC Scientific Equipment, Australia, controlled by Cintral software vs. 2.6.) at its maximum wavelength $\lambda=484 \mathrm{~nm}$. The AO7 concentration was determined by comparing the absorbance to a previously obtained calibration curve. All experiments were performed in triplicate, and the mean values were reported. The amount of anionic dye adsorbed on the GO samples at equilibrium $q_{\mathrm{E}}\left(\mathrm{mmol} \mathrm{g}^{-1}\right)$ was calculated using the following equation:

$$
q_{\mathrm{E}}=\frac{\left(c_{0}-c_{\mathrm{E}}\right) V}{m}
$$

where $c_{0}$ and $c_{\mathrm{E}}\left(\mathrm{mmol} \mathrm{L}{ }^{-1}\right)$ are the initial and equilibrium concentrations, $V(\mathrm{~L})$ is the volume of the solution and $m(\mathrm{~g})$ is the mass of GO in the solution. A slightly modified method ${ }^{21}$ for determining the accessible amino groups was used. Briefly, 750 $\mu \mathrm{L}$ of $4.0 \times 10^{-4} \mathrm{~mol} \mathrm{~L}^{-1} \mathrm{AO} 7,1.050 \mathrm{~mL}$ of BRB and $200 \mu \mathrm{L}$ of the analysed GO were pipetted into $2 \mathrm{~mL}$ Eppendorf vials. The sample processing was in accordance to the previously described methodology.

\section{Results and discussion}

\subsection{Characterization of $\mathrm{GO}$ and $\mathrm{GO}-\mathrm{NH}_{2}$}

The quality of $\mathrm{GO}$ and $\mathrm{GO}-\mathrm{NH}_{2}$ was determined by X-ray diffraction (see Fig. S1 $\dagger$ ) and Raman spectroscopy (see Fig. S2 $\dagger$ ), and the results are presented and discussed in the ESI. $\dagger$

The surface composition of the pristine and aminofunctionalized GO materials was analysed by XPS. Fig. 1 gives the high-resolution $\mathrm{C} 1 \mathrm{~s}, \mathrm{~N}$ 1s and $\mathrm{O} 1 \mathrm{~s}$ spectra of the different GO materials. The individual contributions within the highresolution spectra are reported in Table 1 . The $\mathrm{C} 1 \mathrm{~s}$ spectrum of pristine GO is characterized by contributions at $284.2 \pm 0.1$, 285.0, 285.9 $\pm 0.1,286.5 \pm 0.3,287.7 \pm 0.5$ and $288.8 \pm 0.2 \mathrm{eV}$, arising from the $\underline{\mathrm{C}}=\mathrm{C}$ ( $\mathrm{sp}^{2}$ bonded carbons), $\underline{\mathrm{C}}-\mathrm{C}\left(\mathrm{sp}^{3}\right.$ bonded carbons), alkoxy $\underline{\mathrm{C}}-\mathrm{O}-\mathrm{H}$ (and diminishing $\underline{\mathrm{C}}-\mathrm{N}$ ), ether and epoxy $\underline{\mathrm{C}}-\mathrm{O}-\mathrm{C}$, carbonyl $\underline{\mathrm{C}}=\mathrm{O}$, and ester and carboxy $\underline{\mathrm{C}}(=\mathrm{O})-\mathrm{O}$ moieties, respectively. The weakly pronounced peak at $291.2 \pm$ $0.5 \mathrm{eV}$ arises from the $\pi \rightarrow \pi^{*}$ shake-up transition. The $\mathrm{C} 1 \mathrm{~s}$ spectra clearly show changes in the chemical structure of GO by ammonia treatment. While the $\mathrm{C} 1 \mathrm{~s}$ spectrum of the starting non-modified GO is dominated by strong ether and epoxy contributions ( $c a .28$ at\%) at approximately $286.5 \mathrm{eV}$, the spectrum of GO- $\mathrm{NH}_{2}$ prepared by the herein elaborated method shows only moderate presence of these moieties (not exceeding 5 at $\%)$. The spectrum of commercially available GO-2 (GO-NH SA) shows approximately 18 at\% of these moieties. Strikingly, compared to its unmodified GO counterpart, the GO-1 (GO$\mathrm{NH}_{2}$ ) material is characterized by stronger contributions at approximately $286.0 \mathrm{eV}$. Though strongly overlapped with the alkoxy $\mathrm{C}-\mathrm{O}-\mathrm{H}$ contributions, this observation is indicative of the higher concentration of $\mathrm{C}-\mathrm{N}$ and $\mathrm{C}=\mathrm{N}$ moieties.

Changes due to the introduction of nitrogen species within the GO structure are observed in the high-resolution $\mathrm{N}$ 1s spectra. While the nitrogen contribution in unmodified GO did not overcome 1.4 at $\%$, the total contribution of nitrogen in GO-1 was approximately 6 at\%. Contrary to this, the total nitrogen contribution in commercially available GO-2 was about 3 at $\%$. The N 1s spectra of GO-2, GO-3 and GO-4 showed two contributions at approximately 399.5 and $401.5 \mathrm{eV}$, arising from the amine and charged amine moieties, respectively. The spectra of the prepared GO- 1 showed a significantly higher concentration of these moieties (more than 3 at\% amines) and an additional contribution at approximately $389.5 \mathrm{eV}$, arising from $\mathrm{C}=\mathrm{N}$ aromatic nitrogen. The $\mathrm{O} 1 \mathrm{~s}$ spectra could be fitted with three contributions arising from $\mathrm{O}=\mathrm{C}, \mathrm{O}-\mathrm{C}$ and residual $\mathrm{H}_{2} \mathrm{O}$. The $\mathrm{O}$ 1s spectrum further verified the observation of the reduced presence of ether and epoxy moieties in the GO-1 sample. The XPS data clearly evidenced the more efficient introduction of amine groups by the herein used modification route.

EA confirmed the higher content of nitrogen in all GO- $\mathrm{NH}_{2}$ samples (GO-1 and GO-2), with 3.7\% nitrogen in GO-1 and 4.1\% nitrogen in GO-2. In comparison to the pristine GO samples, where content of nitrogen was negligible, respectively, for GO-3 $0.23 \%$ and GO- $40.53 \%$ of nitrogen. 

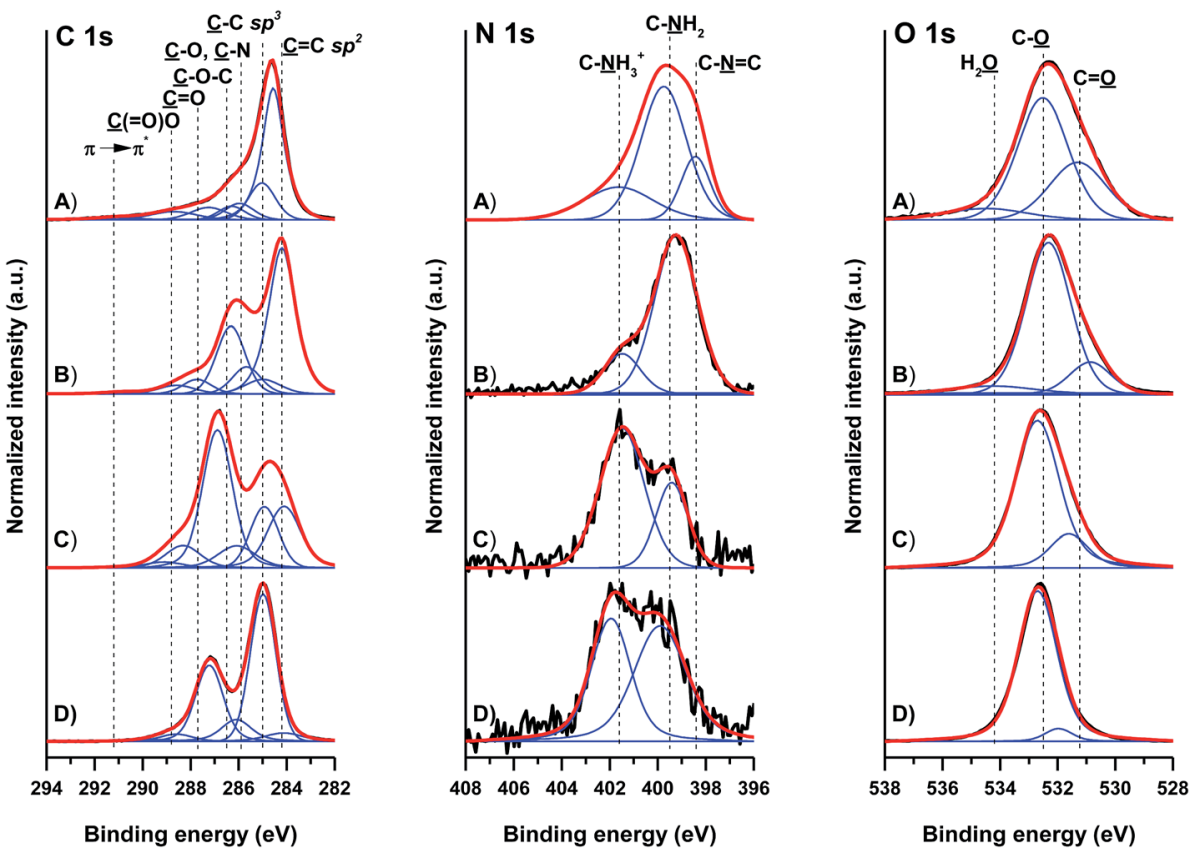

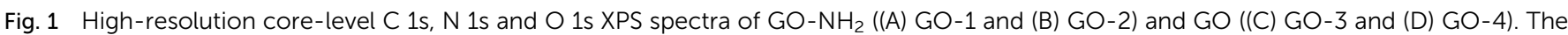
measured spectra are presented with black lines, while their corresponding fitted envelopes are presented in red. The individual contributions of different functional groups present in the materials are represented with blue lines.

Table 1 Contributions of individual chemical moieties in the high-resolution $\mathrm{C}$ 1s spectra of GO-NH 2 (GO-1 and GO-2) and GO (GO-3 and GO4)

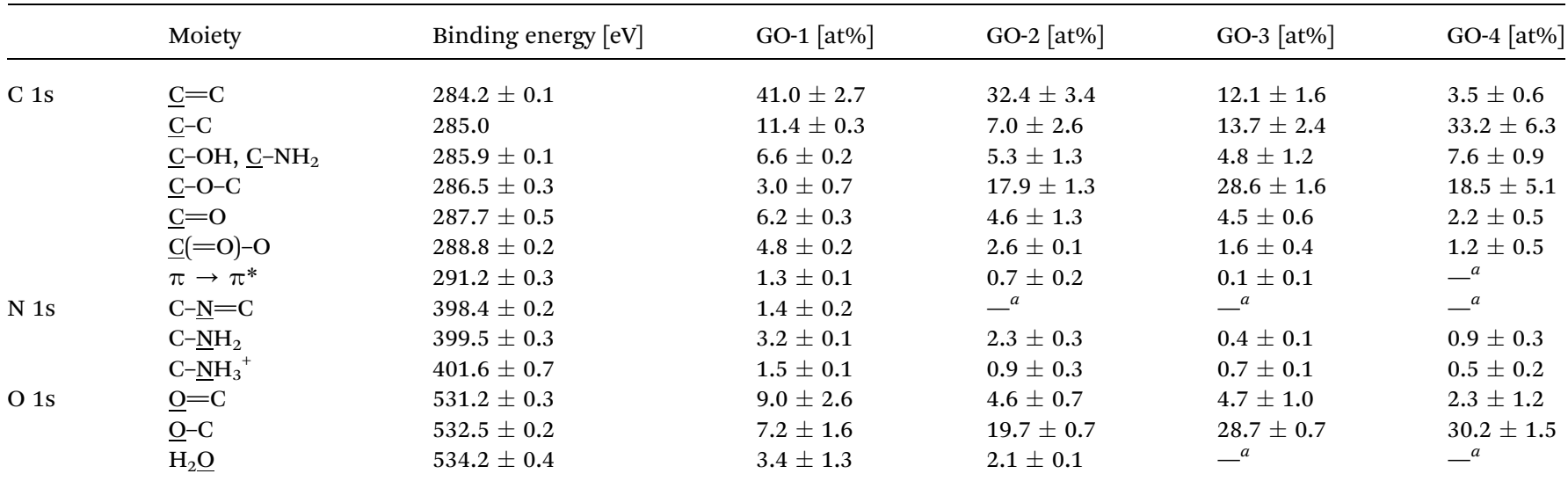

${ }^{a}$ Value was below the detection limit of XPS analysis.

\subsection{Reactivity of GO-NH}

As revealed by XPS analysis (Table 1), the amino-functionalized GO contains sufficient amounts of N-containing groups or moieties of a different nature. In the following experiments, the reaction with isocyanate was used to verify the accessibility of primary amino groups in $\mathrm{GO}-\mathrm{NH}_{2}$ for reaction with $\mathrm{HDI}$ monomer and thus evaluate the potential application of GO$\mathrm{NH}_{2}$ as a functional filler for the preparation of polyurethane nanocomposites. The reaction between the amino groups of GO- $\mathrm{NH}_{2}$ and the isocyanate groups of HDI results in the formation of substituted urea according to Scheme 1.

The progress of the reaction between the primary amino groups of $\mathrm{GO}-\mathrm{NH}_{2}$ and the isocyanate groups of HDI was monitored using ATR-FTIR (Fig. 2). The extent of the reaction was observed from the consumption of isocyanate groups at $2265 \mathrm{~cm}^{-1}$ (Fig. 2A). The peaks at $3325 \mathrm{~cm}^{-1}, 1616 \mathrm{~cm}^{-1}$ and

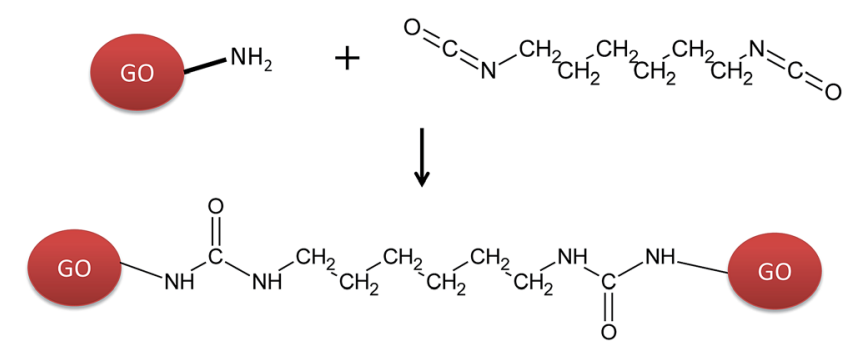

Scheme 1 Reaction scheme of $\mathrm{GO}-\mathrm{NH}_{2}$ and $\mathrm{HDI}$. 

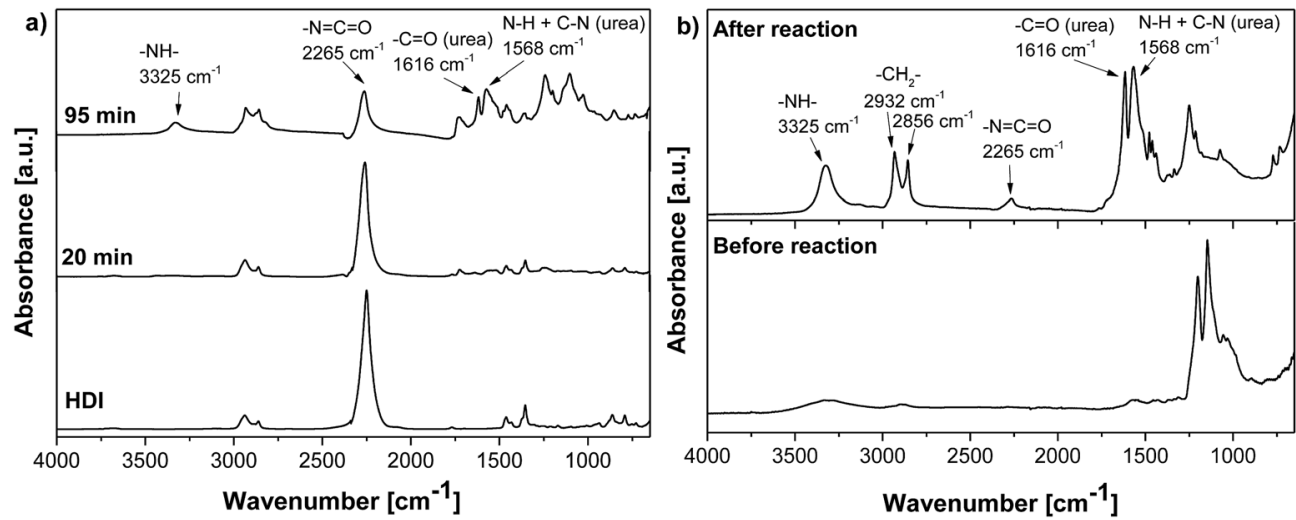

Fig. 2 (A) ATR-FTIR spectra of pure HDI and reaction mixtures after 20 and 95 min of reaction between $\mathrm{GO}-\mathrm{NH}_{2}$ and $\mathrm{HDI}$ in $n$-butyl acetate. (B) ATR-FTIR spectra of dried and washed $\mathrm{GO}-\mathrm{NH}_{2}$ before and after reaction with $\mathrm{HDI}$.

$1568 \mathrm{~cm}^{-1}$ are assigned to $\mathrm{N}-\mathrm{H}$ stretching, amide $\mathrm{I}(\mathrm{C}=\mathrm{O})$ and amide II (a combination peak of $\mathrm{N}-\mathrm{H}$ bending and $\mathrm{C}-\mathrm{N}$ stretching vibrations), respectively, ${ }^{37-41}$ indicating the formation of a urea linkage according to Scheme 1.

Fig. 2B displays the FTIR spectra of the dried and washed GO- $\mathrm{NH}_{2}$ material before and after reaction with HDI. The urea absorption peaks (at $3325 \mathrm{~cm}^{-1}, 1616 \mathrm{~cm}^{-1}$ and $1568 \mathrm{~cm}^{-1}$ ) as well as the peaks at 2856 and $2932 \mathrm{~cm}^{-1}$, corresponding to the symmetric and asymmetric $\mathrm{CH}_{2}$ groups of HDI, are present in the ATR-FTIR spectrum of GO- $\mathrm{NH}_{2}$ after reaction with HDI, which proved the covalent bonding of HDI and the formation of disubstituted urea. The presence of an unreacted NCO band $\left(2265 \mathrm{~cm}^{-1}\right)$ indicates that not all $\mathrm{NH}_{2}$ groups were accessible for reaction with HDI due to steric hindrance.

Contrary to that, the FTIR spectrum of a GO and HDI mixture displayed no significant decrease in the NCO peak $\left(2265 \mathrm{~cm}^{-1}\right)$ with increasing reaction time, indicating that the reaction between GO and HDI practically did not proceed (Fig. 3).

The ATR-FTIR findings were corroborated with the complementary XPS data (Fig. 4 and Table 2). The binding of HDI

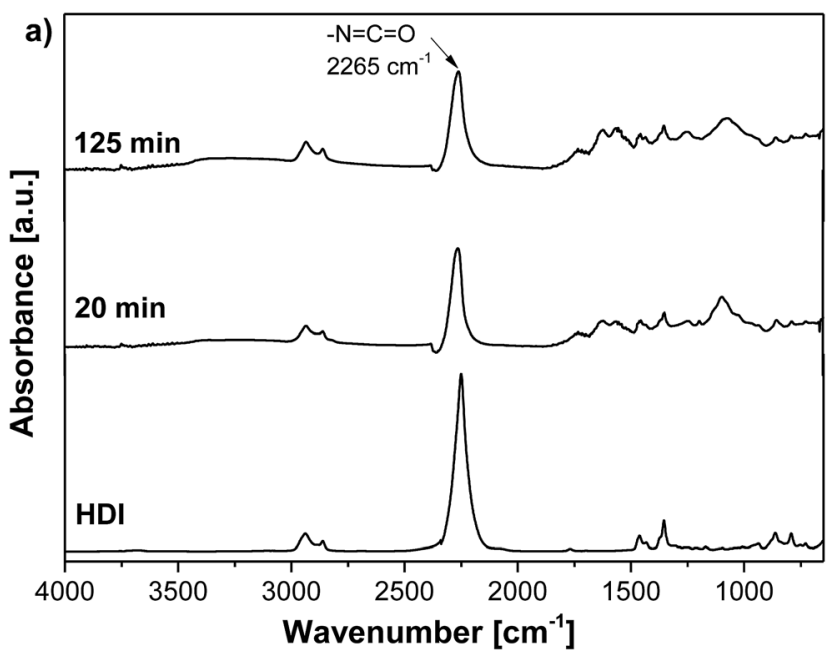

Fig. 3 ATR-FTIR spectra of pure HDI and the reaction mixtures after 20 and 125 min of reaction between GO and HDI in n-butyl acetate. molecules to $\mathrm{GO}-\mathrm{NH}_{2}$ leads to a significant rise in the $\mathrm{sp}^{3}$ carbon contribution and a concomitant rise in the $\mathrm{C}-\mathrm{N}$ moieties at $286.0 \pm 0.1 \mathrm{eV}$ to 18.8 at $\%$. The presence of urea $\mathrm{NH}-\mathrm{C}(=\mathrm{O})-$ $\mathrm{NH}$ moieties, as a product of the covalent bonding of HDI molecules to $\mathrm{GO}-\mathrm{NH}_{2}$, leads to an increase in the originally observed ester and carboxy $\underline{\mathrm{C}}(=\mathrm{O})-\mathrm{O}$ moieties at $288.8 \pm 0.1 \mathrm{eV}$. The presence of HDI molecules is further supported by the increase in the $\mathrm{N} 1 \mathrm{~s}$ signal at $399.8 \pm 0.1 \mathrm{eV}$, originating from the formed urea and unreacted isocyanate groups. Similar trends were observed in the $\mathrm{C} 1 \mathrm{~s}$ and $\mathrm{N} 1 \mathrm{~s}$ spectra of the GO material reacted with HDI. However, the concentration of the formed carbamate $\mathrm{NH}-\underline{\mathrm{C}}(=\mathrm{O})-\mathrm{O}$ groups $(289.0 \pm 0.1 \mathrm{eV})$, as a result of the reaction between the isocyanate groups of HDI and the hydroxyls of GO carbamate, is lower. The lower reactivity of GO is further corroborated by the $\mathrm{N} 1 \mathrm{~s}$ spectra and the presence of up to 7.6 at $\% \mathrm{NH}-\underline{\mathrm{C}}(=\mathrm{O})$ moieties of carbamate and unreacted isocyanate groups.

\subsection{Adsorption isotherm data}

Adsorption isotherms describe the relationship between the adsorbate and adsorbent when the adsorption process reaches an equilibrium state. Langmuir, Freundlich and LangmuirFreundlich isotherms are widely used for describing the relationship between the adsorbed dye concentration and the concentration of the solution at equilibrium. ${ }^{42,43}$ These three adsorption models were also chosen to evaluate our experimental data for $\mathrm{AO} 7$ adsorption to the $\mathrm{GO}-\mathrm{NH}_{2}$ and $\mathrm{GO}$ materials in aqueous solution $\left(25 \pm 1^{\circ} \mathrm{C}\right)$.

The Langmuir adsorption isotherm assumes monolayer adsorption on a homogenous surface. The adsorption process occurs on a surface with a finite number of definite localized sites, which are identical and equivalent. ${ }^{44,45}$ The Langmuir adsorption isotherm in the non-linear form can be expressed by the following equation:

$$
q_{\mathrm{E}}=q_{\mathrm{MAX}} \frac{K_{\mathrm{L}} c_{\mathrm{E}}}{1+K_{\mathrm{L}} c_{\mathrm{E}}}
$$

where $c_{\mathrm{E}}$ is the equilibrium dye concentration $\left(\mathrm{mmol} \mathrm{L}^{-1}\right), q_{\mathrm{E}}$ is the equilibrium amount of dye adsorbed per unit weight of 

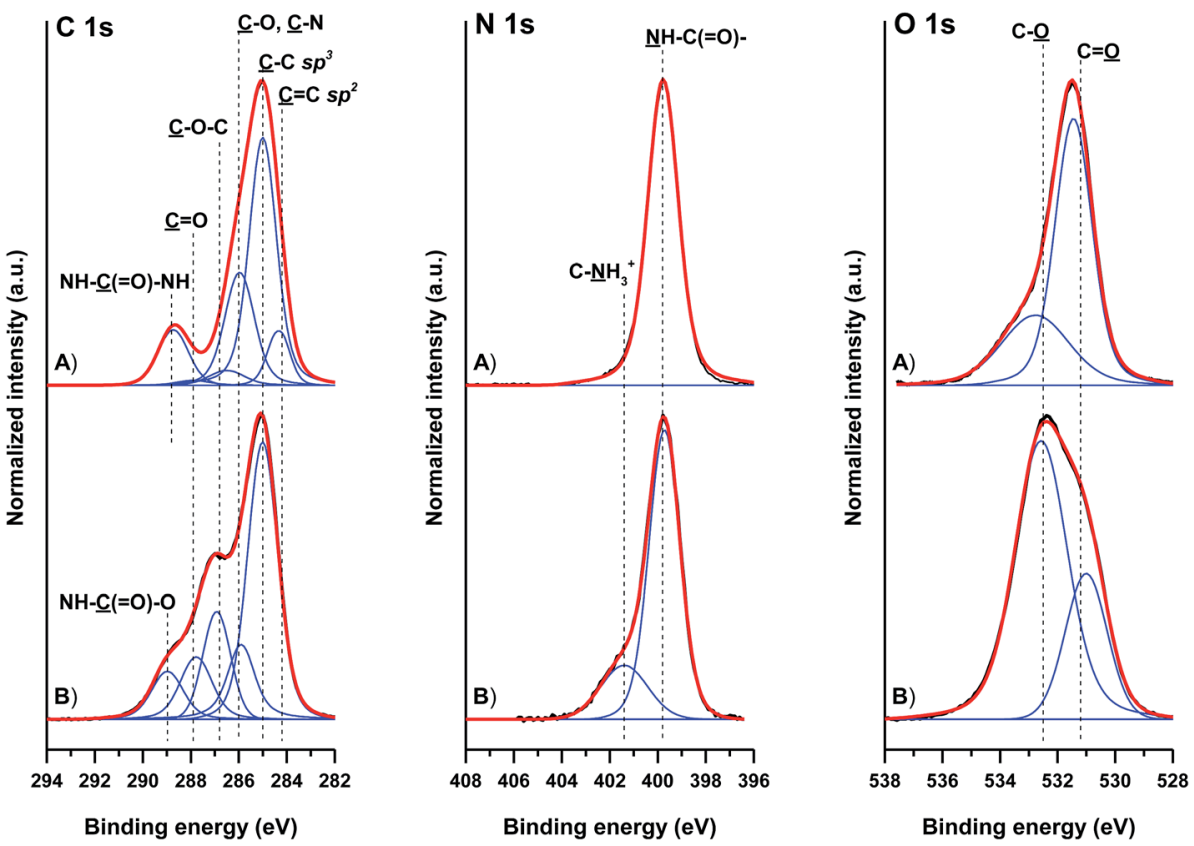

Fig. 4 High-resolution $\mathrm{C} 1 \mathrm{~s}, \mathrm{~N}$ 1s and $\mathrm{O}$ 1s XPS spectra of (A) GO-NH and (B) GO reacted with HDI. The measured spectra are presented with black lines, while their corresponding fitted envelopes are presented in red. The individual contributions of different functional groups present in the GO materials are represented with blue lines.

Table 2 Contributions of individual chemical moieties in the high-resolution $\mathrm{C} 1 \mathrm{~s}, \mathrm{~N}$ 1s and $\mathrm{O}$ 1s spectra of $\mathrm{GO}-\mathrm{NH} \mathrm{H}_{2}$ and $\mathrm{GO}$ after reaction with $\mathrm{HDI}$

\begin{tabular}{|c|c|c|c|c|}
\hline & Moiety & Binding energy $[\mathrm{eV}]$ & $\mathrm{GO}-\mathrm{NH}_{2}+\mathrm{HDI}[\mathrm{at} \%]$ & GO + HDI [at\%] \\
\hline \multirow[t]{5}{*}{ C $1 \mathrm{~s}$} & $\underline{\mathrm{C}}=\mathrm{C}$ & $284.2 \pm 0.1$ & $4.8 \pm 1.6$ & $-^{a}$ \\
\hline & $\underline{\overline{\mathrm{C}}}-\mathrm{C}$ & 285.0 & $33.7 \pm 1.3$ & $34.0 \pm 1.0$ \\
\hline & $\underline{\mathrm{C}}-\mathrm{O}-\mathrm{C}$ & $286.8 \pm 0.3$ & $3.3 \pm 0.6$ & $12.5 \pm 1.3$ \\
\hline & $\underline{\mathrm{C}}=\mathrm{O}$ & $287.9 \pm 0.3$ & $0.7 \pm 0.6$ & $6.7 \pm 1.2$ \\
\hline & $\overline{\mathrm{N}} \mathrm{H}-\mathrm{C}(=\mathrm{O})-\mathrm{NH}$ & $288.8 \pm 0.1$ & $8.7 \pm 0.4$ & $-^{a}$ \\
\hline & $\mathrm{C}-\underline{\mathrm{NH}}_{3}^{+}$ & $401.4 \pm 0.1$ & $-^{a}$ & $1.8 \pm 0.2$ \\
\hline \multirow[t]{2}{*}{ O $1 \mathrm{~s}$} & $\underline{\mathrm{O}}=\mathrm{C}$ & $531.2 \pm 0.3$ & $8.2 \pm 0.3$ & $7.6 \pm 1.1$ \\
\hline & $\overline{\mathrm{O}}-\mathrm{C}$ & $532.5 \pm 0.2$ & $3.2 \pm 0.6$ & $15.4 \pm 1.0$ \\
\hline
\end{tabular}

${ }^{a}$ Value was below the detection limit of XPS analysis.

adsorbent (mmol $\mathrm{g}^{-1}$ ), $q_{\mathrm{MAX}}$ is the maximum amount of dye adsorbed per unit weight of adsorbent to form a complete monolayer coating $\left(\mathrm{mmol} \mathrm{g} \mathrm{g}^{-1}\right)$ and $K_{\mathrm{L}}$ is the Langmuir adsorption constant $\left(\mathrm{L} \mathrm{mmol}^{-1}\right)$.

The Freundlich adsorption isotherm is commonly used for describing non-ideal and reversible adsorption at heterogeneous surfaces. This isotherm is not limited to monolayer formation and is now commonly used for describing adsorption processes of organic compounds on carbon (especially active carbon) materials or molecular sieves. ${ }^{\mathbf{4 4 6}}$ The Freundlich adsorption isotherm in the non-linear form can be expressed by the following equation:

$$
q_{\mathrm{E}}=K_{\mathrm{F}} c_{\mathrm{E}}^{1 / n_{\mathrm{F}}}
$$

where $K_{\mathrm{F}}$ is the Freundlich isotherm constant $\left(\mathrm{L} \mathrm{g}^{-1}\right), n_{\mathrm{F}}$ is the adsorption intensity, $c_{\mathrm{E}}$ is the equilibrium dye concentration ( $\mathrm{mmol} \mathrm{L} \mathrm{L}^{-1}$ ), and $q_{\mathrm{E}}$ is the equilibrium amount of dye adsorbed per unit weight of adsorbent $\left(\mathrm{mmol} \mathrm{g}^{-1}\right)$.

The Langmuir-Freundlich isotherm (L-F) is a useful and versatile isotherm, which combines the advantages and behaviours of the Langmuir and Freundlich isotherms. ${ }^{47}$ Advantageously, at low adsorbate concentration, $\mathrm{L}-\mathrm{F}$ is reduced to the Freundlich isotherm. By contrast, at high concentrations, L-F behaves as a Langmuir isotherm with monolayer adsorption capacity. ${ }^{44}$ The $\mathrm{L}-\mathrm{F}$ equation can be expressed in the following form:

$$
q_{\mathrm{E}}=q_{\mathrm{MAX}} \frac{K_{\mathrm{LF}} c_{\mathrm{E}}^{1 / n_{\mathrm{LF}}}}{1+K_{\mathrm{LF}} c_{\mathrm{E}}^{1 / n_{\mathrm{LF}}}}
$$


where $c_{\mathrm{E}}$ is the equilibrium dye concentration $\left(\mathrm{mmol} \mathrm{L}^{-1}\right), q_{\mathrm{E}}$ is the equilibrium amount of dye adsorbed per unit weight of adsorbent (mmol $\mathrm{g}^{-1}$ ), $q_{\mathrm{MAx}}$ is the Langmuir-Freundlich maximum adsorption capacity $\left(\mathrm{mmol} \mathrm{g}^{-1}\right), K_{\mathrm{LF}}$ is the equilibrium constant for a heterogeneous solid $\left(\mathrm{L} \mathrm{mmol}^{-1}\right)$ and $n_{\mathrm{LF}}$ is the heterogeneity parameter. ${ }^{48}$

Amount of free AO7 after the adsorption experiment was evaluated using the equation obtained from the linear regression of the calibration plot, $y=18062 x+0.0368$, which shows a good correlation coefficient $\left(R^{2}=0.9989\right)$ and RSD $<3 \%$ (see Fig. S3 and $\mathrm{S} 4 \dagger)$. Isotherms were measured in the concentration range of $6.5 \times 10^{-5} \mathrm{~mol} \mathrm{~L}^{-1}$ to $2.5 \times 10^{-4} \mathrm{~mol} \mathrm{~L}^{-1}$. The maximum adsorption amount $\left(q_{\mathrm{MAX}}\right)$, correlation coefficient $\left(R^{2}\right)$, and other parameters of all isotherms are presented in Table 3, and the isotherms are shown in Fig. 5.

According to our experimental data, the adsorption process of AO7 can be described very well by the Freundlich and LangmuirFreundlich models under the concentration range studied. Very good fit to the Freundlich model for the AO7 dye (GO-1 and GO-2) suggests that the surface is heterogeneous. Adsorption is limited with multilayer coverage and interaction between the adsorbed molecules. The heterogeneity parameter $n_{\mathrm{F}}$ is used to indicate whether the adsorption is a chemical process $\left(n_{\mathrm{F}}<1\right)$, a physical process $\left(n_{\mathrm{F}}>1\right)$ or linear $\left(n_{\mathrm{F}}=1\right)$. A value of $1 / n_{\mathrm{F}}<1$ or $1 / n_{\mathrm{F}}>1$ indicates normal adsorption; otherwise, it is indicative of cooperative adsorption. The measured values of $n_{\mathrm{F}}>1$ and $1 / n_{\mathrm{F}}<1$ indicate that the physical process and Langmuir isotherm model are favourable for all samples.

On the other hand, in the case of the Langmuir isotherm model, there is a very important parameter, $R_{\mathrm{L}}$ (separation factor). The separation factor $\left(R_{\mathrm{L}}\right)$, calculated using eqn (5) (results are not presented), can be used to verify whether the adsorption of the studied systems is favourable $\left(0<R_{\mathrm{L}}<1\right)$, irreversible $\left(R_{\mathrm{L}}=0\right)$, linear $\left(R_{\mathrm{L}}=1\right)$ or unfavourable $\left(R_{\mathrm{L}}>1\right)$.

$$
R_{\mathrm{L}}=\frac{1}{1+K_{\mathrm{L}} c_{\mathrm{E}}}
$$

The values of $R_{\mathrm{L}}<1$ under our conditions (concentration range of $2.5 \times 10^{-4}$ to $4.5 \times 10^{-5} \mathrm{~mol} \mathrm{~L}^{-1}$ ) indicate favourable adsorption in the AO7-GO- $\mathrm{NH}_{2}$ system.

The Langmuir constant $K_{\mathrm{L}}$ relates to the affinity of the binding sites for the adsorbate. ${ }^{49}$ It can be said that the affinity

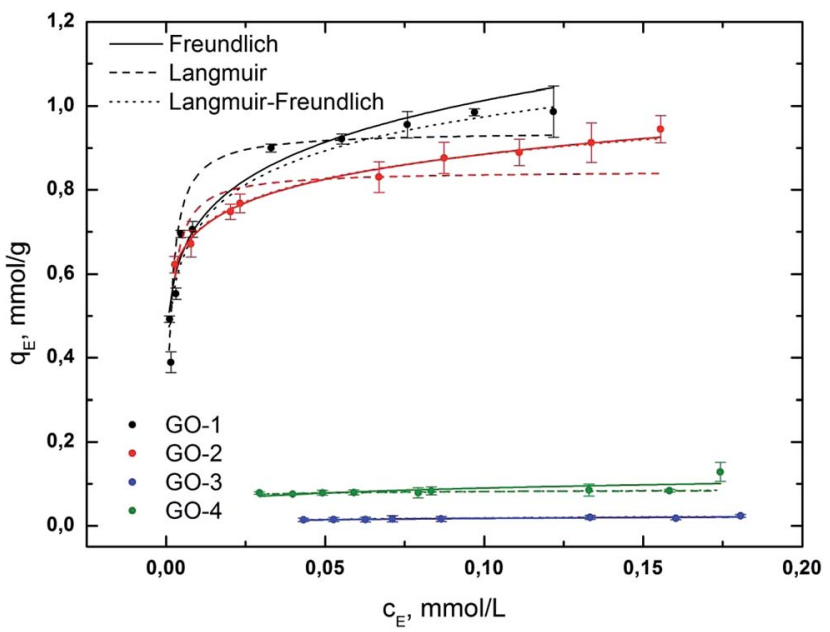

Fig. 5 Fits of the Freundlich (solid line), Langmuir (dashed line) and Langmuir-Freundlich (dotted line) isotherms for the adsorption of AO7 on GO samples (GO-1 to GO-4).

of the AO7 dye decreases in the order of GO-2 > GO-1 > GO-4> GO-3.

The heterogeneity parameter, obtained from the L-F model, confirmed our observation that the adsorption process of the dye corresponded to the Freundlich model. However, the samples GO-3 and GO-4 did not follow any of the used isotherms.

The negligible adsorption of GO- 3 and GO- 4 is caused by the limited presence of non-protonated functional groups or the intercalation of $\mathrm{AO} 7$ into the GO structure. It can be said that all tested $\mathrm{GO}-\mathrm{NH}_{2}$ samples (GO-1 and GO-2) are perspective sorbents with relatively high sorption capacities of anionic dyes under our studied conditions. We suppose that the higher sorption capacity of GO- $\mathrm{NH}_{2}$ is probably caused by the presence of accessible protonated amino groups (probably in the form of $-\mathrm{NH}_{3}{ }^{+}$), which easily interact with $-\mathrm{SO}_{3}{ }^{-}$in the $\mathrm{AO} 7$ dye. We found that the non-ammonia-functionalized samples GO-3 and GO-4 are not very effective sorbents for anionic dyes, which is not in compliance with certain results in the available literature..$^{45,50}$

The total amount of accessible amino groups in the GO and GO- $\mathrm{NH}_{2}$ samples obtained by the sorption of $\mathrm{AO} 7$ are presented in Table 4.

Table 3 Freundlich, Langmuir and Langmuir-Freundlich model constants and correlation coefficients for the adsorption of AO7 onto GO samples

\begin{tabular}{|c|c|c|c|c|c|c|c|c|c|c|}
\hline Sample & \multicolumn{3}{|l|}{ Freundlich } & \multicolumn{3}{|l|}{ Langmuir } & \multicolumn{4}{|c|}{ Langmuir-Freundlich } \\
\hline GO-1 & 1.428 & 6.714 & 0.9532 & 810.9 & 0.940 & 0.8799 & 2 & 1.849 & 3.937 & 0.9392 \\
\hline GO-2 & 1.118 & 9.873 & 0.9905 & 850.9 & 0.845 & 0.6995 & 0.5 & 3.281 & 7.585 & 0.9858 \\
\hline GO-3 & 0.035 & 3.313 & 0.6906 & 26.0 & 0.025 & 0.6483 & 0.5 & 0.105 & 2.770 & 0.5038 \\
\hline
\end{tabular}

${ }^{a}$ Fixed parameters. 
Table 4 The amount of amino groups (number of performed measurements $n=3$ ) on the GO-NH$H_{2}(\mathrm{GO}-1$ and GO-2) and GO (GO3 and GO-4) samples, determined by $\mathrm{AO} 7$ absorption after 3 hours of equilibration

\begin{tabular}{lll}
\hline Sample & $q_{\mathrm{NH}_{2}}\left(\mathrm{mmol} \mathrm{g}^{-1}\right)$ & RSD $(\%)$ \\
\hline GO-1 & 0.85 & 0.59 \\
GO-2 & 0.83 & 2.58 \\
GO-3 & 0.02 & 1.63 \\
GO-4 & 0.09 & 4.08
\end{tabular}

The contents of the amino groups estimated from the AO7 adsorption are significantly lower the content of nitrogen determined by EA, which can be explained by the presence of another type of $\mathrm{N}$-containing functional groups (nonaccessible). We supposed that by using the AO7 adsorption method, we were able to determine only the amount of accessible amino groups (functional speciation), which correlated well with the stoichiometry of the GO- $\mathrm{NH}_{2}$-HDI reaction mentioned above. The results in Table 4 show that there was a significant amount of amino groups present in the GO- $\mathrm{NH}_{2}$ samples, while the non-functionalized GO samples (GO-3 and GO-4) contained practically zero accessible amino groups. The calculated values for the GO-3 and GO-4 samples can be probably ascribed to the weak interaction of $\mathrm{AO} 7$ with GO surface functionalities or the intercalation of $\mathrm{AO} 7$ into the structure of GO but not to the accessible amino groups.

\subsection{Characterization of samples before and after sorption of $\mathrm{AO7}$}

Changes in the samples before and after sorption of $\mathrm{AO} 7$ dye were observed by FTIR (Fig. 6 and 7) and TEM (Fig. 8). The FTIR spectrum of pristine AO7 (shown in Fig. 6 and 7) contained the most important bands located in the region of $2000-1000 \mathrm{~cm}^{-1}$. The band at $1512 \mathrm{~cm}^{-1}$ was assigned to $-\mathrm{N}-\mathrm{H}$ bond vibrations, ${ }^{51-53}$ and according to Zhang et al., the band at $1447 \mathrm{~cm}^{-1}$ corresponded to the azo bond vibration..$^{53,54}$ The band at 1625

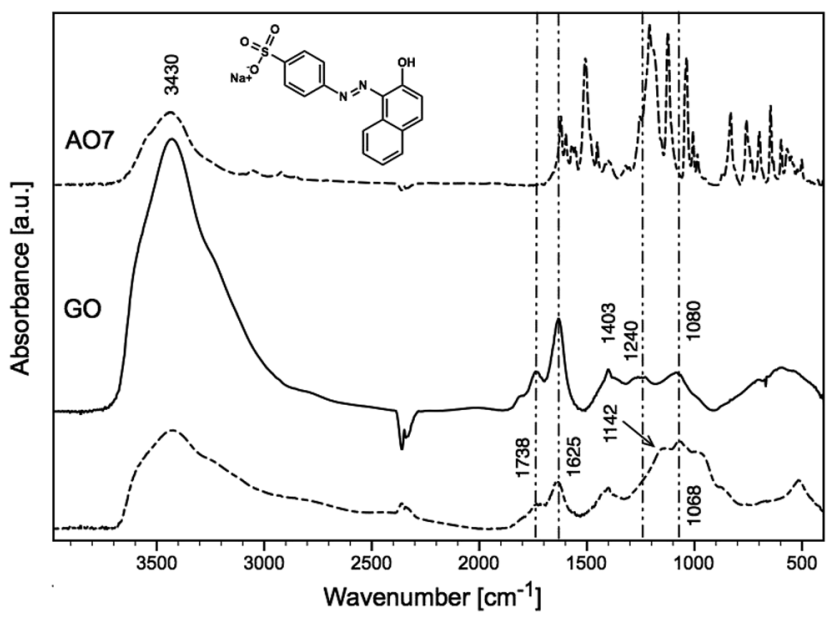

Fig. 6 FTIR spectra of GO-3 before (solid line) and after (dashed line) AO7 sorption.

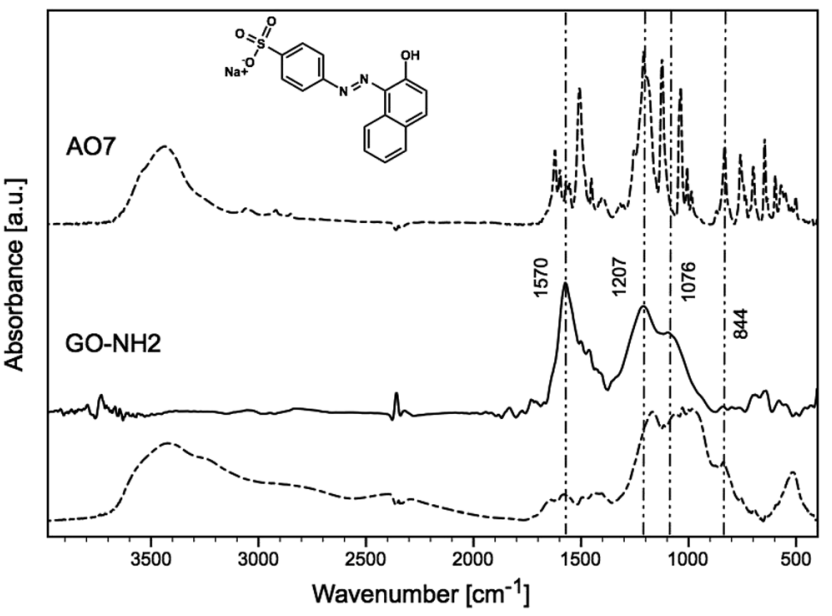

Fig. 7 FTIR spectra of GO-1 before (solid line) and after (dashed line) AO7 sorption.
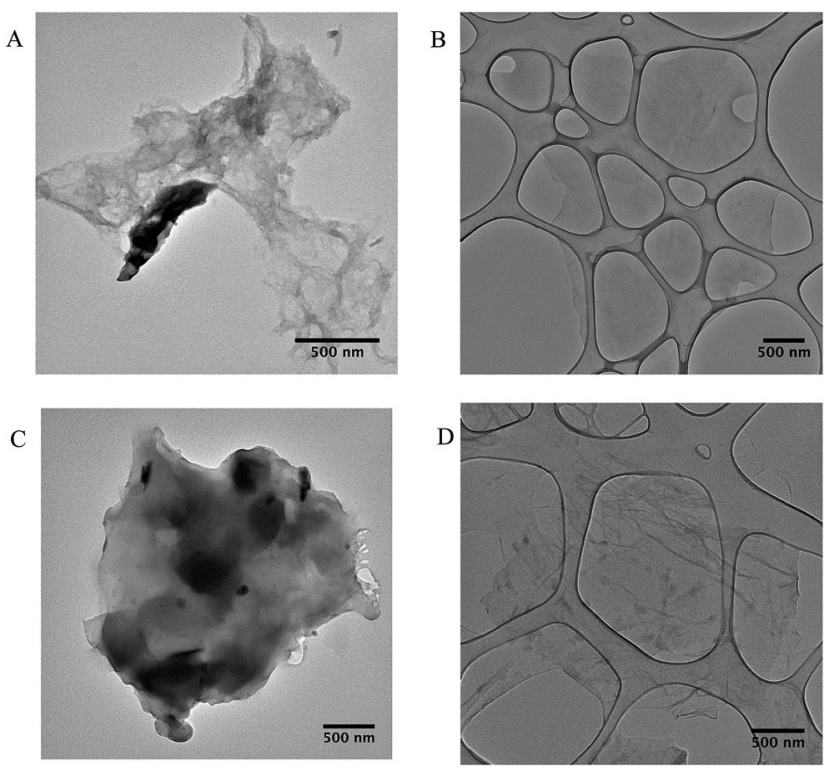

Fig. 8 TEM images of GO-1 before (A) and after (C) sorption, GO-3 before (B) and after (D) sorption.

$\mathrm{cm}^{-1}$ was a combination of phenyl ring vibrations and $\mathrm{C}=\mathrm{N}$ stretching group. ${ }^{53}$ The bands in region $1600-1450 \mathrm{~cm}^{-1}$ were linked to characteristic aromatic $\mathrm{C}=\mathrm{C}$ vibrations. ${ }^{51,53,54}$ The bands located in the region of $1250-1000 \mathrm{~cm}^{-1}$ were assigned to the S-O stretching ${ }^{52,54}$ and aromatic $=\mathrm{C}-\mathrm{H}$ bending vibrations. ${ }^{54}$ The peaks at 1036 and $1127 \mathrm{~cm}^{-1}$ corresponded to the coupling between the benzene mode and $\nu_{\mathrm{s}}\left(\mathrm{SO}_{3}\right) .^{53}$ The FTIR spectra of GO before and after (dashed line) sorption of AO7 are shown in Fig. 6. The typical vibrations of GO at 3424, 1738, 1625, 1403, 1240 and $1080 \mathrm{~cm}^{-1}$ were observed for $\mathrm{O}-\mathrm{H}$ stretching, $\mathrm{C}=\mathrm{O}$ stretching, $\mathrm{C}=\mathrm{C}$ stretching, $\mathrm{O}-\mathrm{H}$ deformation, $\mathrm{C}-\mathrm{O}$ epoxy stretching, and $\mathrm{C}-\mathrm{O}$ alkoxy stretching bands. ${ }^{55}$ The FTIR spectra of GO-NH before and after (dashed line) sorption of AO7 are shown in Fig. 7. The amination causes the attenuation of 3424, 1738, 1240 and $1080 \mathrm{~cm}^{-1}$ vibrations. The typical bands of primary amines, $\mathrm{N}-\mathrm{H}$ 
and $\mathrm{C}-\mathrm{N}$ stretching vibrations, were observed at 1570, 844 and $1207 \mathrm{~cm}^{-1} .^{10,49}$ It should be noted that the bands were expanded and shifted by approximately $10 \mathrm{~cm}^{-1}$ for the out-of-plane $\mathrm{N}-\mathrm{H}$ bending vibrations from 841 to $834 \mathrm{~cm}^{-1}$.

The band at $1600 \mathrm{~cm}^{-1}$ (Fig. 7) can be assigned to the $\mathrm{N}-\mathrm{H}$ stretching of amine groups, ${ }^{\mathbf{1 0 , 1 2 , 1 7}}$ and after the adsorption of AO7, this band disappeared. This can be explained by the interaction of the dye with the amine groups, as seen in Fig. 7, where the bands appearing in the region $1250-1000 \mathrm{~cm}^{-1}$ corresponded to $\mathrm{S}-\mathrm{O}$ stretching (from $-\mathrm{SO}_{2}$ of the dye). ${ }^{52,54}$ The band at $1190 \mathrm{~cm}^{-1}$, which appeared after the adsorption of AO7, can also be assigned to the sulfonate group vibration, ${ }^{56}$ and band at $1443 \mathrm{~cm}^{-1}$ probably to $\mathrm{N}=\mathrm{N}$ stretching. ${ }^{53}$ The same results were observed for the second sample. From the results discussed above, we assume that the $\mathrm{AO} 7$ dye reacted specifically with the amino groups of GO- $\mathrm{NH}_{2}$.

The TEM images (Fig. 8) display the different morphologies of the GO and GO- $\mathrm{NH}_{2}$ samples before and after AO7 sorption. No significant morphological differences were found in the GO3 sample (Fig. 8B and D) before and after AO7 sorption, showing the minimal sorption affinity to the $\mathrm{AO} 7$ dye. Contrary to that, the amino-functionalized sample GO-1 (Fig. 8A and C) showed morphological changes caused by the sorption of AO7 dye and subsequent agglomeration. This observation confirmed our assumption that $\mathrm{AO} 7$ dye interacts specifically with the GO-NH surface under the selected experimental conditions.

\section{Conclusions}

It follows from the investigations of the $\mathrm{GO}-\mathrm{NH}_{2}$ reactions with isocyanate monomer that the $\mathrm{NH}_{2}$ groups on the GO surface play a key role in the preparation the polyurethane nanocomposites. We developed a simple and fast method to determine the amount of amino groups accessible for the reaction with isocyanate monomer. Together with XPS, these methods provide valuable and complementary information about the $\mathrm{GO}-\mathrm{NH}_{2}$ reactivity and allow to evaluate the potential applicability of $\mathrm{GO}-\mathrm{NH}_{2}$ as a functional polymer filler. The quantification of accessible primary amino groups was done using the spectrophotometric method based on the interaction of positively charged groups with the anionic dye AO7. All amino-functionalized samples exhibited higher affinity to AO7 dye, contrary to GO samples without $\mathrm{NH}_{2}$ groups. It was found that ammonia-functionalized GO samples are perspective sorbents for anionic dyes under the selected conditions, contrary to non-functionalized GO samples, according our results. The presence of amino groups on the GO$\mathrm{NH}_{2}$ surface was also confirmed by FTIR and XPS, and the presence of nitrogen was determined by EA.

The accessibility of amino groups of $\mathrm{GO}-\mathrm{NH}_{2}$ was successfully verified by reaction with HDI, demonstrating the perspective application of $\mathrm{GO}-\mathrm{NH}_{2}$ as a functional filler for polymer composites.

\section{Acknowledgements}

This work was supported by the Grant Agency of the Czech Republic, grant no. 14-05146S. OPG acknowledges support from the European Regional Development Fund OPPK (CZ.2.16/ 3.1.00/21545).

\section{References}

1 M. S. Nevius, M. Conrad, F. Wang, A. Celis, M. N. Nair, A. Taleb-Ibrahimi, A. Tejeda and E. H. Conrad, Phys. Rev. Lett., 2015, 115, 136802.

2 K. S. Novoselov, Z. Jiang, Y. Zhang, S. V. Morozov, H. L. Stormer, U. Zeitler, J. C. Maan, G. S. Boebinger, P. Kim and A. K. Geim, Science, 2007, 315, 1379.

3 E. C. Marino, L. O. Nascimento, V. S. Alves and C. M. Smith, Phys. Rev. X, 2015, 5, 11040.

4 D. A. C. Brownson, L. J. Munro, D. K. Kampouris and C. E. Banks, RSC Adv., 2011, 1, 978.

5 W. S. Hummers and R. E. Offeman, J. Am. Chem. Soc., 1958, 80, 1339.

6 X. Wang, W. Wang, Y. Liu, M. Ren, H. Xiao and X. Liu, Anal. Chem., 2016, 88, 3926-3934.

7 M. Inagaki and F. Kang, J. Mater. Chem. A, 2014, 2, 13193.

8 N. Oger, Y. F. Lin, C. Labrugère, E. Le Grognec, F. Rataboul and F. X. Felpin, Carbon, 2016, 96, 342-350.

9 S. Sandoval, N. Kumar, J. Oro-Solé, A. Sundaresan, C. N. R. Rao, A. Fuertes and G. Tobias, Carbon, 2015, 96, 594-602.

10 L. Lai, L. Chen, D. Zhan, L. Sun, J. Liu, S. H. Lim, C. K. Poh, Z. Shen and J. Lin, Carbon, 2011, 49, 3250-3257.

11 Y. Shao, J. Sui, G. Yin and Y. Gao, Appl. Catal., B, 2008, 79, 89-99.

12 T. Ramanathan, F. T. Fisher, R. S. Ruoff and L. C. Brinson, Chem. Mater., 2005, 17, 1290-1295.

13 M. Fan, C. Zhu, Z.-Q. Feng, J. Yang, L. Liu and D. Sun, Nanoscale, 2014, 4882-4888.

14 T. Van Khai, H. G. Na, D. S. Kwak, Y. J. Kwon, H. Ham, K. B. Shim and H. W. Kim, Carbon, 2012, 50, 3799-3806.

15 W. Zhang, J. Ma, D. Gao, Y. Zhou, C. Li, J. Zha and J. Zhang, Prog. Org. Coat., 2016, 94, 9-17.

16 H. Zhang, T. Kuila, N. H. Kim, D. S. Yu and J. H. Lee, Carbon, 2014, 69, 66-78.

17 J. Shen, W. Huang, L. Wu, Y. Hu and M. Ye, Mater. Sci. Eng. A, 2007, 464, 151-156.

18 A. Navaee and A. Salimi, RSC Adv., 2015, 5, 59874-59880.

19 E. Blanco, G. Blanco, J. M. Gonzalez-Leal, M. C. Barrera, M. Domínguez and M. Ramirez-del-Solar, J. Nanopart. Res., 2015, 17, 214.

20 M. Prato, K. Kostarelos and A. Bianco, Acc. Chem. Res., 2008, 41, 60-68.

21 L. Fras Zemljic, S. Strnad, O. Sauperl and K. StanaKleinschek, Text. Res. J., 2009, 79, 219-226.

22 V. Mittal, Macromol. Mater. Eng., 2014, 299, 906-931.

23 D. Galpaya, Graphene, 2012, 1, 30-49.

24 F. Perreault, A. Fonseca de Faria and M. Elimelech, Chem. Soc. Rev., 2015, 44, 5861-5896.

25 D. Cai, J. Jin, K. Yusoh, R. Rafiq and M. Song, Compos. Sci. Technol., 2012, 72, 702-707.

26 X. Luo, P. Zhang, J. Ren, R. Liu, J. Feng and B. Ge, J. Appl. Polym. Sci., 2015, 132, UNSP 42005. 
27 S. Wu, T. Shi and L. Zhang, High Perform. Polym., 2016, 28, 453-465.

28 D. K. Patel, R. K. Singh, S. K. Singh, V. K. Aswal, D. Rana, B. Ray and P. Maiti, RSC Adv., 2016, 6, 58628-58640.

29 G. Gabriel, G. Sauthier, J. Fraxedas, M. Moreno-Mañas, M. T. Martínez, C. Miravitlles and J. Casabó, Carbon, 2006, 44, 1891-1897.

30 C. Samorì, R. Sainz, C. Ménard-Moyon, F. M. Toma, E. Venturelli, P. Singh, M. Ballestri, M. Prato and A. Bianco, Carbon, 2010, 48, 2447-2454.

31 S. L. Goertzen, K. D. Thériault, A. M. Oickle, A. C. Tarasuk and H. a. Andreas, Carbon, 2010, 48, 1252-1261.

32 G. Coussot, C. Perrin, T. Moreau, M. Dobrijevic, A. Postollec and O. Vandenabeele-Trambouze, Anal. Bioanal. Chem., 2011, 399, 1061-1069.

33 T. T. Ngo, J. Biochem. Biophys. Methods, 1986, 12, 349-354.

34 N. Rao, S. Agarwal, V. Chauhan, D. Bhatia, a. Sharma, P. Kumar, B. Garg and K. Gupta, Anal. Chim. Acta, 2000, 247-254.

35 V. Štengl, Chem.-Eur. J., 2012, 18, 14047-14054.

36 V. Stengl, S. Bakardjieva, T. M. Grygar, J. Bludská and M. Kormunda, Chem. Cent. J., 2013, 7, 41.

37 J. Shang, S. Liu, X. Ma, L. Lu and Y. Deng, Green Chem., 2012, 14, 2899.

38 L. May-Hernández, F. Hernández-Sánchez, J. L. GomezRibelles and R. Sabater-i Serra, J. Appl. Polym. Sci., 2011, 119, 2093-2104.

39 T. Jiang, X. Ma, Y. Zhou, S. Liang, J. Zhang and B. Han, Green Chem., 2008, 10, 465.

40 M. M. Coleman, M. Sobkowiak, G. J. Pehlert, P. C. Painter and T. Iqbal, Macromol. Chem. Phys., 1997, 198, 117-136.
41 J. Mattia and P. Painter, Macromolecules, 2007, 40, 15461554.

42 V. K. Konaganti, R. Kota, S. Patil and G. Madras, Chem. Eng. J., 2010, 158, 393-401.

43 Y. A. Aydın and N. D. Aksoy, Chem. Eng. J., 2009, 151, 188194.

44 K. Y. Foo and B. H. Hameed, Chem. Eng. J., 2010, 156, 2-10.

45 G. K. Ramesha, A. Vijaya Kumara, H. B. Muralidhara and S. Sampath, J. Colloid Interface Sci., 2011, 361, 270-277.

46 A. Dada, A. Olalekan, A. Olatunya and O. Dada, IOSR J. Appl. Chem., 2012, 3, 38-45.

47 G. P. Jeppu and T. P. Clement, J. Contam. Hydrol., 2012, 129130, 46-53.

48 O. Hamdaoui and E. Naffrechoux, J. Hazard. Mater., 2007, 147, 381-394.

49 F. Fang, L. Kong, J. Huang, S. Wu, K. Zhang, X. Wang, B. Sun, Z. Jin, J. Wang, X. J. Huang and J. Liu, J. Hazard. Mater., 2014, 270, 1-10.

50 D. Robati, B. Mirza, M. Rajabi, O. Moradi, I. Tyagi, S. Agarwal and V. K. Gupta, Chem. Eng. J., 2016, 284, 687-697.

51 M. Stylidi, D. I. Kondarides and X. E. Verykios, Appl. Catal., B, 2003, 40, 271-286.

52 M. Stylidi, D. I. Kondarides and X. E. Verykios, Appl. Catal., B, 2004, 47, 189-201.

53 G. Zhang, J. Qu, H. Liu, A. T. Cooper and R. Wu, Chemosphere, 2007, 68, 1058-1066.

54 S.-J. Zhang, H.-Q. Yu and Q.-R. Li, Chemosphere, 2005, 61, 1003-1011.

55 S. Bose, T. Kuila, A. K. Mishra, N. H. Kim and J. H. Lee, J. Mater. Chem., 2012, 22, 9696.

56 L. Y. Liu, M. Pu, L. Yang, D. Q. Li, D. G. Evans and J. He, Mater. Chem. Phys., 2007, 106, 422-427. 